\title{
Charlottesville Urban Design and Affordable Housing:
} A Research and Design Project Sponsored by the
Institute for Advanced Technology in the Humanities'

\author{
KENNETH A. SCHWARTZ \\ University of Virginia \\ USA
}

\section{INTRODUCTION}

One of the most pressing problems confronting architects and planners involves the erosion of urban fabric in American cities and small towns. Many factors have contributed to the physical and economic decline of previously healthy cities since the end of World War II. Federal tax policies involving home mortgage deduction, FHA loan programs, and highway policy and subsidies have all conspired to promote suburban sprawl and a concurrent abandonment of city centers by the middle class. Nowhere has the impact of this problem been felt more seriously than in the area of housing. ${ }^{2}$ The legacy of the late 1950's and 1960's "urban renewal" has decimated vast tracts of land. In many areas of many cities, lower and middle income housing stock has been eliminated, often leaving a wasteland of parking in its place.

This research project addresses the specific context of Charlottesville, Virginia as a town that demonstrates many of the results of urban decay found in cities throughout North America. Through the vehicle of analysis and design, this project explores the application of sensible and traditional principles of town planning to various neglected or ruined areas of the city. ${ }^{3}$ The process of understanding a particular area of a small town requires an appreciation for the regional and historical forces that have produced the contemporary urban condition. In addition to the preliminary research and analysis, specific design proposals are explored for a series of "infill" areas that are currently abandoned, underdeveloped or largely neglected. These areas include the abandoned tracks of the so-called "CSX property" and its associated Belmont neighborhood, the Vinegar Hill neighborhood, the Starr Hill neighborhood, and the area surrounding the University of Virginia Hospital. All four of these areas include primarily low-income housing with predominantly African-American populations and students in the vicinity of the University. In many respects, the four indicated areas of Charlottesville are emblematic of similar challenges that can be found in many small towns. In this sense, research into traditional town planning principles and their application to this specific setting can lead to lessons that may be applied prototypically in other settings as well. Each area of study includes low and moderate income residents and housing with the potential for a clear localized sense of community within the larger city of Charlottesville; there are several important differences amo ng the areas as well, principally in terms of topographic conditions and the proximity to various pressures on development in their immediately surrounding area.

The successful revitalization of these areas depends on an effective integration of multiple uses within a neighborhood setting. The most important aspect of any healthy urban fabric is the housing stock. As an independent but closely related second stage of this research project, we will explore detailed development of affordable housing strategies for these areas. To revive small towns, one must identify strategies for building both economically and with concern for traditions and patterns of life that characterize the best of small town settings. In this research, previous efforts with affordable housing strategies are explored, including both design principles and constructional considerations. In addition to the work of graphically codifying the available information and existing research in this area, the design work concentrates on assembly guidelines and standardization to generate economies of scale and efficiency in the production of housing prototypes. Typological and vernacular study of evolved traditions in housing can help in forming the basis for a return to more sensible and sensitive small town urbanism. Within this study, we are particularly interested in the possibility of using the strong housing traditions of Charlottesville and the surrounding region as the basis for proposals that try to reconcile these precedents with modern methods of assembly and construction.

New town planning proposals from a variety of contemporary practitioners and theorists have provided effective and convincing alternatives to the automobile oriented culture of suburban highway strip development. ${ }^{4}$ However, most of these projects, and their specific architectural elaboration, have been directed toward an upper end, relatively high-income housing market; they have not, for the most part, addressed lower and middle income housing. As architects, we must respond to the challenges of building within contemporary society with conviction about the efficacy of 
design in ameliorating some of the problems that affect cities. But we should also be wary of easy formulas in housing that can be appropriated and quickly consumed. To put these concerns in another perspective, a return to fundamental principles of pre-W.W.II town planning prevalent throughout the United States and Great Britain need not produce a simultaneous nostalgia about an architecture of pure historical quotation. Rather, housing must begin to address fundamental shifts in the way that it is produced, various approaches to the needs of different "clients" must be considered and a wide range of delivery systems and applications should be proposed. This project combines and reconciles traditional town planning principles with essential concerns about modest and low cost housing.

\section{METHODOLOGY}

This project studies specific areas within Charlottesville while, at the same time, establishing a computer based model and methodology that can be utilized in other cities as well. In each area of the study, the computer is used to collect and synthesize primary materials. ${ }^{5}$ In addition, the computer is mobilized to support links with public agencies and to promote community participation in studying development patterns and opportunities in various neighborhoods. With an interactive basis in the research and design work, the concerned public can become directly involved in understanding and shaping healthy neighborhoods. Recognizing and registering concerns and insights that citizens have in shaping their own immediate and civic environment provides a meaningful voice for those who have been largely excluded from any formative role in the past. The ability to synthesize and organize a vast range of material and to present it clearly suggests a compelling way to bring design issues before the public. ${ }^{6}$ In addition, the interactive model has been designed to facilitate feedback and direct input from those who review the material, exploring the various options and considerations presented. This information in turn influences and builds the body of research itself, thus producing something of a cyclical and cross-referencing process.

The interactive computer "text" includes traditional narratives of the city's history; oral histories from neighborhood residents; a compilation and transformation of maps at various points in the history of Charlottesville; historic and contemporary views; videotape recordings of significant sequences and animated representations of proposed urban design strategies; catalogs of housing types in plan, elevation and image format; and the collection of previous efforts with affordable housing strategies from the past. This material forms the basis of transformational work in the architectural design portion of the project. For example, aspects of the urban history of Charlottesville are reconstituted in a way that provides a compelling direction for future development based upon patterns that derive from the past. In a similar vein, new housing strategies are developed and proposed as modern adaptations of traditional patterns of dwelling and residential construction.
This project, including the text and various forms for graphic and visual support, is available to anyone with an Internet connection through the "World Wide Web" (http:/ /jefferson.village.virginia.edu). These commands bring up the home page for the Institute for Advanced Technology in the Humanities at the University of Virginia which has sponsored and supported this research; look under "Work in Progress". This "interactive" access allows community groups and other architects to participate in the ongoing research as it develops. The presentation at the ACSA Annual Meeting will utilize the interactive features afforded by this technology. For the purpose of this article, I have chosen to restrict the presentation to the narrative text dealing with one neighborhood. Ahead of this description lies a larger urban history (in text, maps, diagrams and views) of Charlottesville itself. $^{7}$ Given the vast range of material included in the computer archive, and with the understanding that this visual material is best understood "interactively", I have chosen to wait until the ACSA meeting in Seattle to provide a more holistic presentation. Bold items in this text indicate links with additional graphic material contained within the electronic document.

\section{VINEGAR HILL: A BRIEF URBAN HISTORY}

In the most strict interpretation, "Vinegar Hill" refers to the segment of West Main Street as it moves from Second Street, SW up to Fourth Street. Early in the nineteenth century, this portion of Main Street also acquired the name of Random Row in recognition of the way that the street deviates from the regular grid of the original town plan. The gentle curve of the street, combined with a rather steep incline produced a series of stepping and mostly detached structures along both sides of the street. Most interpretations would suggest that the triangular area defined by Main Street on the South, Preston Avenue on the north and Fourth Street on the west constitutes the Vinegar Hill area, immediately to the west of the original downtown grid of Charlottesville. Stories and accounts from the nineteenth century and early twentieth century are ambiguous in explaining the origination of the name for this neighborhood. James Alexander, writing in 1874 and reflecting back to the early part of the century, recounts the reputation of the area as a center for moonshining in Charlottesville:

"Here properly ends Random Row, called by many 'Vinegar Hill'. The first name was probably obtained from the random way the houses were put up, without reference to the old town lines; at the head of the hill the street is much narrower than at its foot. Mr. J. Frank Fry tells us that the name 'Vinegar Hill' was given to it on account of the illicit trade carried on in the sale of distilled liquors by persons doing business as grocers' they labeled the casks containing spirits, 'Vinegar'. We have often heard this street called purgatory, as it was a very bad road to travel, rough, rocky and steep; accidents to carriages and vehicles often occurring. 
Since the street became a part of the town, the authorities have graded and macadamised it, and now it is in as good condition as the rest of our streets."

Alexander goes on to indicate another interpretation of the name's origin, relating to the old Irish fighting song by the same name:

"....and this brings us back to the foot of the hill, and the beginning of Random Row, or "Vinegar Hill". The latter name we have since been informed, was given to it by George Toole, and he named it in honor of the Vinegar Hill in Ireland, where the O'Toole's lived, an account of which can be seen in Lever's novel of Charles O'Malley, The Irish Dragoon."'

Many of the early residents of this neighborhood were Irish immigrants, several hundred of whom moved into town with the rail construction crews around 1850 . There were several drinking establishments along Main Street, and apparently fights were quite common. Mary Rawlings indicates in her footnotes to the Alexander Recollections;

"Under the stimulus of sufficient conviviality, one part would ally forth to 'clean out' the other. The old Irish fighting song of 'Vinegar Hill' would be raised and adherents would flock to both standards. Where the Lewis and Clark monument now is situated was an open space with town pump and trough which furnished the battle ground, the vanquished being finally ducked in the trough and rolled in the mud. There was a saying that the O'Tooles, the O'Tracys and the O'Donovans ruled Vinegar Hill......We are told that the older dwellers on this street insisted that the proper name was 'the Hill', and considered the later name (Vinegar Hill) a nickname."10

Rawlings also identifies the possible role of at least one tannery that was located at the base of the hill; the foul smells of this operation could have also contributed to the name for the area. Apparently water played a prominent role in the identity of this area. Several springs existed toward the top of the hill, and many of the houses in the area had their own wells. Water flowed freely in a drainage pattern that moved directly through the neighborhood. In John Hammond Moore's book on Albemarle County, he cites a moving account of the area from an editorial entitled "Art and Nature in Town" dated June 22, 1860 in the Review:

"'We have in our midst one of the wildest and most romantic chasms in the mountains of Virginia. Indeed Charlottesville combines to a greater degree than any village we know the diverse attractions of city and country.' Describing in glowing detail perils and vistas to be encountered as one walked along a ravine carrying water from the Vinegar Hill area to Wills's Ice Pond in what is now the 200 block of Preston Avenue, the editors continued, 'Like the traveler over some Alpine pass, the danger will add to the vividness of his feelings. The best time to go is on your way to evening service at the Episcopal Church - when the moon is over spread by some black cloud. One inch to the right will break both legs, and if the torrent is up, sweep you romantically under the planks and under the fence - 'down to the endless seas'. We do not know who designed this. It is greatly superior to the Serpentine in London, or those artificial cascades in the Bois de Boulogne. It was a good thought, to have a real ravine amid the hum of a city, and when after a rain the water comes thundering down, the view is sublime ... It was left to the giants of an inland town in Virginia to develop the idea of a civic ravine - a mountain gorge amid the populous haunts and the confined air of a busy municipality."'l1

During the Civil War, Midway Hospital was built at the intersection of Main Street and Old Lynchburg Road (Ridge Street) atop Vinegar Hill. The hospital served as one of three facilities supporting the Confederate effort. Between 1861 and 1865 , over 20,000 soldiers were ministered by these hospitals.

In 1893, the Midway School was built on the site of the former hospital. Around the turn of the century, nearly 1500 students were enrolled at Midway (all local white students). Black students were enrolled exclusively at Jefferson School, at the western edge of the Vinegar Hill neighborhood (Commerce and Fourth Streets). By 1925 three more schools were added within the city (McGuffy-1916, Venable-1925 and Clark-1931) but these were grade schools for white students only. Approximately 250 black students were enrolled at Jefferson, but the school continued only through eighth grade. In 1926 Jefferson was enlarged to accommodate the black students who wished to continue their high school education; before this date, any interested students had to leave town beyond the eighth grade.

Throughout the early part of the twentieth century, Vinegar Hill emerged as an important center of commerce for the black community of Charlottesville. Sanborn maps clearly indicate a wide range of small scale industrial and service businesses that were located in this area. In addition, many small detached homes and at least three churches occupied the irregular sites between Main Street and Preston Avenue. Several recollections were included from City of Charlottesville's oral history project of the mid 1980s. From Porch Swings to Patios ${ }^{12}$ includes several revealing accounts. Each of these individuals touch on some aspect of life around West Main Street or in the Vinegar Hill neighborhood: Ella Baylor, George Ferguson, Thomas Ferguson Inge, Sr., Rebecca McGinness. These accounts identify the segregation that was a fundamental fact of life in small southern towns. It is within this context that one must understand the jarring effects of school desegregation following the Supreme Court decision of Brown vs. Board of Education in 1954. Under segregationist governors, communities within the Commonwealth of Virginia fought the 
federal imperative of desegregation. ${ }^{13}$ The "battle" surrounding this issue had a particular impact on the Vinegar Hill neighborhood, because the white high school had been built at the base of the Hill on Preston Avenue, while black students remained in separate facilities at Jefferson School and elsewhere in the city. The process of "urban renewal" in the 1960's directly paralleled the fight to avoid integration by city leaders.

Vinegar Hill was largely demolished in the mid-1960's as a part of Charlottesville's "urban renewal" campaign. The political forces within the city saw a derelict slum that had developed on the hillside immediately adjoining the downtown district. At the same time, peripheral areas beyond downtown had begun to draw commerce away from the central district and some form of revitalization was seen as necessary to staunch the flow. In addition, there was no smooth north-south connection through the downtown area of Charlottesville, and ease of automobile and bus transportation was seen as a high priority, especially for the Greyhound franchise which stood at the top of Vinegar Hill on Main Street. All of these factors combined with available federal money and a very thinly disguised racist agenda of slum clearing in an area so close to the reputable downtown business district to produce the nearly wholesale destruction of a neighborhood that was uncommonly rich in its own heritage, traditions and lore within Charlottesville.

The elimination of the principal area of commerce for the African-American population of Charlottesville, in close proximity to the city high school, cannot be seen in isolation. While the community only temporarily succeeded in avoiding integration, the destruction of Vinegar Hill has had a profound and long lasting effect on the identity and economic health a formerly cohesive neighborhood. As early as 1976, John Hammond Moore identified some of the many shortcomings of such a violent urban act:

"The Hill, now swept bare by an urban renewal scheme which seems to have faltered, then had forty-one buildings on the north side of the street and sixteen on the south..... Vinegar Hill did not burn down nor did all the "bad folks" disappear when that sordid but colorful jumble of buildings was razed. Center of bootleg activity and vice it was, but the hill most assuredly was much more vibrant and alive in its former guise than it is today, now merely an expanse of bare ground stretching like a no-man's-land, perhaps to be the site of the downtown business district's last stand should the upstart shopping centers mushrooming a few miles to the west ever launch an all-out attack"14

The hope of an area, cleared of unhygienic slums, miraculously evolving into a vibrant component of a revitalized downtown district has not been realized. Urbanistically, the area has followed a number of planning and architectural formulas from the 1950's and 60's. These involve the primacy of the automobile in its smooth operation at fairly high speeds through the city, serviced and supported by ample areas of grade parking, in which an occasional building is placed. As a strategy, this is in direct contrast to the fundamental relationship that existed in this area between building and street, between a clearly discernible front versus back of each property, between the amenities and social support of the public realm.

It would be impossible to resurrect Vinegar Hill in its earlier form, and few would be interested in the problems of drainage and the absence of sewer hookups and running water that many of the properties had to endure. However, some form of reconstruction can be imagined, and one hopes that this new interest in the area can seriously consider the rich history of the place and the memory of its former residents.

\section{NOTES REGARDING THE APPLICATION OF THIS RESEARCH}

The reconstruction of North American urban fabric is a widespread concern. Many communities are struggling with ways to redirect their energies to meet the urgent need for affordable housing. The computer platform supports a community oriented, participatory design process based on specific historical antecedents that are particular to a given community, along with a "kit of parts" for the construction assembly of various housing units within the town. The computer based approach will yield strategies that can be readily transported to other comparable community settings. The work of this research should support a renewed interest in rehabilitation and redevelopment where the particular urban history and patterns of dwelling within a community emerge as primary forces, guided by informed community involvement. This, in turn, could form the basis for considered community action in the planning and rebuilding of the often fragmentary conditions that dominate most small town urban settings.

\section{NOTES}

Specific Uses of Information Technology: In collaboration with the staff at the Institute for Advanced Technology in the Humanities at the University of Virginia and several other key contributors (Earl Mark, Assistant Professor of Architecture, Paul Schulhof, Caryn Brause and Marjorie Tether, Graduate Research Assistants), various techniques have been explored and utilized in this project. The techniques include the following:

A. Animation for simulation of urban environments and video for assembling and disseminating results of the analysis and design work: This technology establishes an easy basis for visualizing the effects of urban growth and transformation. Various considerations including topographic conditions, land use patterns, zoning constraints and economic factors exert forces on the formation of communities. Computer technology helps to organize information and variables, thus assisting a community in considering multiple options in their planned (or sometimes unplanned) growth. Animation and simulation are used as tools in the collection and organization of research material and as a medium for the demonstration and involvement by the public in the results of the design and research work. 
B. Graphic Information System (GIS) for the study of housing and development patterns: Current GIS technology can provide valuable imaging for housing development patterns. The process of charting growth and transformation begins to provide specific suggestions about ways that neighborhoods can develop with full recognition of their past conditions, building on the positive attributes that may have once existed. Many of these attractive qualities in the small town setting are currently threatened by "outside" forces and pressures. One of the most notable examples of this concern in Charlottesville is the area surrounding the University of Virginia Medical Center. This neighborhood has a rich tradition dating back to the early nineteenth century, yet its particular identity and attributes have been seriously challenged and threatened by the ever expanding Medical Center. In the more distant past, the Vinegar Hill neighborhood was decimated in the name of "urban renewal", eliminating one of the most important and vibrant residential and commercial areas of Charlottesville's African-American community during the nineteen-sixties. A careful recognition of patterns and particular local conditions provides a much more constructive model for developing and reinforcing individual neighborhoods. GIS technology and the other computer based approaches explored in this project can strongly promote public appreciation for the community's heritage.

C. Computer Aided Design (CAD) for geometric modeling: Information from GIS is collected and primarily presented in a two-dimensional format. At the same time, threedimensional modeling is important in demonstrating a more tangible and "real" simulation of familiar urban and topographic conditions. One example of this application involves the demonstration of current and future zoning constraints on building footprints and massing within various neighborhoods. Zoning laws are written documents and they currently require "translation" into three-dimensional terms. The public, politicians and planning departments seldom understand the specific physical and formal implications of the zoning laws that are currently written. Geometric modeling can demonstrate current conditions and new approaches that more convincingly approximate the familiar settings of traditional small town planning.

Geometric modeling also applies to work involving specific housing studies. A computer based approach is patterned on the "Sears Catalog House" from the early part of this century, in which various combinations of standardized assembly elements can be organized by home owners. The computer technology allows individuals to quickly visualize economical possibilities within a graphically defined "kit of parts" of housing options. Rather than relinquishing this process of "product development" and individual participation in the organization of housing options to free-market forces of speculative development, our design study proposes a more sensitive relationship between current affordable housing practice and traditions from the past. This connection between specific affordable options in housing and a relationship to familiar practices in the past reinforces the previously described role of re-uniting a neighborhood's development with patterns of evolution as identified through the GIS and urban design work.

D. Digital image archival systems for compiling data about the built environment. This aspect of work ties into the Digital Image Center (DIC) in the Fine Arts Library at the University of Virginia. Ongoing work in the DIC supports this research project in several ways. Documenting the urban history of Charlottesville involves digital imaging technology. For example, digitized urban plans of compa- rable settings within North American have been considered as we explored initial settlement patterns and the changes that occur under the influence of individually identified factors. The DIC promotes more synthetic and perhaps unexpected associations among urban precedents than those that might be identified through traditional graphic, statistical, and representational approaches. In the area of housing, the DIC assists in collecting and cataloguing options and combinations that one can extract from the vernacular architectural history and vernacular traditions of this region.

${ }^{2}$ The literature on this condition is quite extensive. James Howard Kunstler's book, The Geography of Nowhere: The Rise and Decline of America's Man-made Landscape, provides an excellent account.

3 Traditional town planning alludes to a series of "innovations" in contemporary practice which recognize the value and cohesion of the street and the importance of neighborhoods in the social fabric of small town settings.

${ }^{4}$ Elizabeth Plater-Zyberk and Andres Duany, Peter Calthorpe, Stefanos Polyzoides and Elizabeth Moule, and Leon Krier (among many others) have all explored pedestrian oriented possibilities while at the same time recognizing the realities of the ubiquitous automobile in contemporary society.

5 This project does not follow the approach demonstrated by Mario Gandelsonas in some of his recent work. His book, The Urban Text, presents a rather limited view of the computer's role in his approach to analyzing the city. His use of the computer renders issues as purely graphic representations. Nowhere in his approach is the computer used to support tangible design proposals nor are perceptual qualities and experience within a city explored.

- Citizen involvement has always been important in the social fabric of healthy neighborhoods. Recent planning practices in many communities have tried to embrace feedback and input through staged events, often called "Visioning Sessions". Unfortunately, this approach is almost entirely devoid of any formal content, focusing instead on "bubble diagrams" of community desires. These sessions often seem to devolve into group encounters, and even when the organizers feel that they have been successful, the lasting impact and influence is limited by the absence of tangible design direction. The "charrettes" of Duany, Plater-Zyberk and others have been much successful because design issues are the focus of discussion and exploration.

${ }^{7}$ Not surprisingly, the history of Charlottesville and Albemarle County has been extensively documented in books, articles, dissertations, biographies, etc. The computer "text" contains a very extensive bibliographic listing. Among the most impressive articles dealing with the urban and architectural heritage of Charlottesville is K. Edward Lay's, "Charlottesville's Architectural Legacy", The Magazine of Albemarle County History, Vol. 46, Charlottesville, May, 1988.

8 James Alexander, Early Charlottesville: Recollections of James Alexander 1828-1874, Edited by Mary Rawlings, Albemarle County Historical Society, Charlottesville, 1942, p. 100.

9 Alexander, ibid. p. 110.

10 Alexander, ibid. pp. 98, 100.

"John Hammond Moore, Albemarle, Jefferson's County, 17271976, University Press of Virginia, Charlottesville, 1976, p. 165.

12 Wilma T. Mangione, editor, From Porch Swings to Patios: An Oral History Project of Charlottesville Neighborhoods, 19141980, The City of Charlottesville, 1990.

${ }^{13}$ Charlottesville's part in the movement of "massive resistance" was prominent; it was one of three communities which specifically challenged the federal imperative of 
school integration through court challenges. Contemporary newspaper articles document the drawn out period of controversy, and several scholarly articles and books have revisited this period. Among these are: Alexander De Mont, The Denouement of Virginia's Massive Resistance to Desegregation: The closing of the Schools in Charlottesville, Norfolk and Warren County, Thesis, University of Oxford,
1978. Anna Holden, The Bus Stops Here: A Study of School Desegregation in Three Cities, Agathon Press, Schocken Books, New York, 1974. Paul Gaston and Thomas T. Hammond, Public School Desegregation: Charlottesville, Virginia, 1955-1962, University of Virginia Printing Services, Charlottesville, 1962.

14 Moore, op.cit., pp. 429, 430. 